\title{
Imaginarios en disputa o sobre la territorialización de un conflicto urbano. El caso de "La Canchita de los Bomberos" (Mar del Plata, Argentina)
}

Imaginários em disputa ou sobre a territorialização de um conflito urbano. O caso da "Canchita de los Bomberos" (Mar Del Plata, Argentina)

Imaginaries in dispute or on the territorialization of an urban conflict. The case of "Canchita de los Bomberos" (Mar del Plata, Argentina)

María Laura Canestraro

Universidad Nacional de Mar del Plata (UNMDP), Consejo Nacional de Investigaciones Científicas y Técnicas (CONICET),

Mar del Plata, Buenos Aires, Argentina

\section{Resumen}

Apenas transcurridos tres meses de la creación del "Programa Crédito Argentino del Bicentenario para la Vivienda Única Familiar", el Municipio de General Pueyrredón anuncia las tierras disponibles para comprometer en su implementación; entre ellas, el predio conocido como "Canchita de los Bomberos" de la ciudad de Mar del Plata. Frente a ello, se conforma un grupo de vecinos autoconvocados en defensa de su utilización como espacio público-verde, llevando a cabo diversas estrategias cuyo objetivo es evitar la construcción de viviendas en esa zona. Paralelamente, otras personas manifiestan su parecer en relación a la ejecución del programa y desarrollan prácticas que cuestionan la legitimidad de las demandas sostenidas por aquellos vecinos. El propósito del artículo es analizar las formas de apropiación simbólica que se refuerzan y/o modifican en función de la disputa; lo que Melé (2003) llama "el proceso de territorialización del conflicto". Se argumenta que, aunque se produce un choque de imaginarios (Hiernaux; 2008a), emerge un imaginario dominante que logra imponerse y legitimar el uso y disfrute del espacio a su favor.

Palabras Clave: Políticas urbanas. Territorialización. Imaginarios urbanos.

Resumo

Apenas três meses após a criação do "Programa Crédito Argentino del Bicentenario para la Vivienda Única Familiar", o município de General Pueyrredón anuncia terra disponível para confirmar sua implementação; entre as terras a área conhecida como "Canchita de los Bomberos", na cidade de Mar del Plata. Em resposta, um grupo de vizinhos une-se para defender o uso público, a fim de impedir a construção de moradias na área. Paralelamente, outras partes interessadas expressaram suas opiniões sobre a implementação do programa em desenvolver práticas que disputam a legitimidade das reivindicações dos vizinhos. $O$ objetivo do trabalho é analisar as formas de apropriação simbólica reforçando e/ou modificado em função do litígio; o que Melé (2003) chama de processo de territorialização. Argumenta-se que, mesmo que haja um choque de imaginário (Hiernaux, 2008a), surge um imaginário dominante que consegue impor e legitimar o uso e gozo do espaço em seu favor.

Palavras-chave: Políticas Urbanas. Territorialização. Imaginário urbano.

MLC es Licenciada en Sociología (UNLP), magister en Ciencia y Filosofía Política (UNMDP), doctora en Ciencias Sociales (UBA), e-mail: mlcanestraro@gmail.com 


\section{Abstract}

Only three months after the establishment of the "Programa Crédito Argentino del Bicentenario para la Vivienda Única Familiar", the municipality of General Pueyrredón announces land available to commit to its implementation, including the area known as "Canchita de los Bomberos" in the city of Mar del Plata. In response, a group of neighbors conforms to defend its public use holding to various strategies in view of preventing the construction of housing in that area. In parallel, other stakeholders expressed their views on the implementation of the program and develop practices that dispute the legitimacy of the claims held by those neighbors. The purpose of the paper is to analyze the forms of symbolic appropriation reinforced and/or modified in light of the dispute; what Mele (2003) calls the process of territorialization. We argue that, while a clash of imaginary (Hiernaux, 2008a) occurs, a dominant imaginary emerges and manages to impose and legitimize the use and enjoyment of the space in its favor.

Keywords: Urban Policies. Territorialization. Urban Imaginary.

Este artículo ${ }^{1}$ forma parte de un estudio más amplio que analiza la productividad social de un conflicto (Mele, 2003) derivado del posible destino de un predio de tierras para la construcción de viviendas en el marco de una política pública, el Programa Crédito Argentino del Bicentenario para la Vivienda Única Familiar (PRO.CRE.AR). Siguiendo a Melé, esto supone abordar sus efectos sociales desde tres ángulos: la territorialización, que alude a las formas de apropiación simbólica del espacio que suelen reforzarse o modificarse en función del conflicto, la irrupción del conflicto en el espacio público, que remite a las formas de deliberación pública en que el conflicto es procesado y la actualización local del derecho, que refiere a la juridificación del conflicto y, con ello, a las resignificaciones y transformaciones que se producen una vez que ingresa al mundo del derecho (Azuela \& Mussetta, 2009; Azuela \& Cosacov, 2013)2 .

En este caso, analizaremos un conflicto de proximidad (Mele, 2003) ${ }^{3}$ centrándonos en el

\footnotetext{
${ }^{1}$ Una versión preliminar fue presentada en las VII Jornadas de Investigación en Antropología Social, Instituto de Ciencias Antropológicas/Universidad de Buenos Aires, en noviembre de 2013 (Canestraro, 2013).

${ }^{2}$ En el estudio mayor se indagan las tres dimensiones del conflicto, que se abordan de manera progresiva. Con fines analíticos, en este artículo hemos decidido profundizar en la primera de ellas.

${ }^{3}$ Para Melé la proximidad refiere a aquella definición que dan los residentes cuando un proyecto afecta su entorno. Si bien aquí nos proponemos indagar las múltiples representaciones e imaginarios que coadyuvan a diferentes formas de apropiación simbólica y ello excede, en sentido estricto, a las de los vecinos
}

proceso de territorialización. Nos preguntamos ¿qué representaciones simbólicas emergen en el conflicto?, ¿se construyen imaginarios urbanos en la disputa o a causa de ella?, ¿son preexistentes?, ¿trascienden el territorio y se vinculan con esferas más amplias o más bien se acotan al mismo?, ¿cómo se vincula este proceso a la dinámica y estructura urbana de la ciudad?, etc.

Con ese propósito realizamos un estudio de caso ${ }^{4}$, recurriendo a una diversidad de fuentes: entrevistas en profundidad a vecinos, normativa existente e información periodística, boletines vecinales, publicaciones realizadas en redes sociales y revelamiento fotográfico. A partir de ello, en primer lugar, revisamos la historia del predio en cuestión, analizando sus múltiples usos y destinos y haciendo hincapié en el origen de la actual disputa. Seguidamente, profundizamos en la construcción de representaciones e imaginarios en el conflicto. Finalmente, ponemos en relación los puntos de vistas captados, no sólo para develar el proceso de territorialización en sí mismo sino para vincularlo a la producción de la ciudad y lo urbano.

que se verían afectados; consideramos que resulta útil para definir el conflicto, incorporándole además las prácticas de quienes también tienen intereses en dicha intervención (potenciales beneficiarios, Municipio, etc.), a pesar de que no residan en ese territorio.

${ }^{4}$ Como sostienen Neiman \& Quaranta (2006, p. 219), “[...] la elección del caso busca maximizar las posibilidades y la capacidad que las condiciones y características del caso presentan para desarrollar conocimiento a partir de su estudio. La muestra es intencionada en función de los intereses temáticos y conceptuales [...]". 


\section{Del solarium al PRO.CRE.AR: usos y destinos de la "Canchita de los Bomberos"}

En su origen, las tierras que se hallan en disputa pertenecen a María Luro de Elissathe Chevalier, quien fuera hija de Pedro Luro, uno de los principales propietarios del partido General Pueyrredon. Por ello, posteriormente se delimita sobre ellas el barrio que alude a aquel: Parque Luro.

Hacia inicios de la década de 1900, algunas de estas hectáreas pasan a ser propiedad de la familia Unzué que destina el predio en cuestión a la construcción de un Solarium para el tratamiento de la tuberculosis en niños, dependiendo del Sanatorio Marítimo ${ }^{5}$.

En el año 1947 se crea la Sociedad de Vecinos Zona Parque Luro. A partir de ella comienzan a canalizarse diversas reclamaciones orientadas a urbanizar la zona $^{6}$. En 1949, se reconoce oficialmente la Sociedad de Fomento Parque Luro. También se emplaza en el barrio el Destacamento del Cuerpo de Bomberos, aledaño al terreno que se halla en disputa, que se denomina así debido a que es el lugar históricamente utilizado para actividades recreativas de los bomberos.

Hacia 1950 se disuelve la Sociedad de Beneficencia, que gestionaba la donación de la familia Unzué, y se transfieren sus bienes al patrimonio nacional del Estado. Según relata el informe técnico realizado a pedido del grupo de vecinos autoconvocados ${ }^{7}$, ya por el año 1951 "surgió la necesidad de una plaza pública sugiriéndose las cuatro manzanas delimitadas por Strobel, Rocha, Cardiel y Mármol”. Una década más tarde, hacia 1960, al erradicarse la enfermedad que había motivado su construcción -la tuberculosis-, el Solarium queda abandonado y las autoridades no dan ningún uso al edificio. Fue a partir de inicios de la década de 1980 que, con la demolición del Solarium, se suscitaron diversas disputas en torno a los usos y destinos del predio. Todavía sigue con destino incierto.

\footnotetext{
${ }^{5}$ Es inaugurado en 1918 por la presidenta de la Sociedad de Beneficencia de la Capital Federal, María Unzué de Alvear, que está al mando de ambas instituciones. También tiene a su cargo al Asilo Unzué, destinado a asilar niñas huérfanas.

${ }^{6}$ Extensión del alumbrado público, recogida de residuos domiciliarios, etc.

7 “Impacto por el cambio de uso del predio 'Canchita de los Bomberos"', coordinado por Arq. Fernández Bravo, Arq. Ondartz y Lic. Rivera. y presentado en 29 de abril de 2013 en el auditorio de la Asociación Bancaria de Mar del Plata.
}

En 1985, se reservan parcelas para "la construcción futura de un Centro de Convenciones y Congresos Nacionales e Internacionales con Sala de Conciertos y Hotel de cinco (5) estrellas" (Argentina, 1985). Para ello, se modifica su uso residencial de baja densidad-, afectándose como "Distrito Urbanización futura".

En 1990, se declaran de interés municipal "las fracciones no construidas de propiedad de los gobiernos nacional y provincial, y de sus empresas y organizaciones descentralizadas, ubicadas en el Partido de Gral. Pueyrredon" (Argentina, 1990). Si bien esta normativa alude con vaguedad a una diversidad de inmuebles, en 1991 se señala el interés del municipio por gestionar la cesión de las fracciones fiscales del predio en cuestión (Argentina, 1991).

En 1996, intentan instalar un parque de diversiones, pero el Ejecutivo municipal deniega el permiso de uso del suelo (Decreto 0063/96). Dicha medida obedece a dos razones: que los usos solicitados difieren del uso que permite el catastro del predio ${ }^{8}$, y que se tuvo en cuenta la proporción de vecinos que se oponían a la instalación de dicho parque de diversiones ${ }^{9}$.

Para 1997, se establece en la normativa urbanística como "Centro Cultural de Convenciones y Hotel Cinco Estrellas", desafectándose parcialmente como distrito de Urbanización Futura y ordenándose la apertura de tramos cedidos y no abiertos al público; y una parte donada al uso público, definiéndose además en diversos tramos el terreno dedicado a nuevas edificaciones. Asimismo, se declaran de utilidad pública y sujeta a expropiación dos de las parcelas del predio para que sean destinadas a espacio verde y libre, es decir, de uso público (Argentina, 1997).

En 1998, se convalida un convenio por el cual el Estado Nacional designa a la municipalidad como "depositaria en custodia del inmueble propiedad de aquel [...] hasta tanto el Estado Nacional determine el destino final del predio en el marco de lo dispuesto en las normas que rigen la materia", reservándose el derecho de revocar el convenio; y, si así fuera,

\footnotetext{
${ }^{8}$ El uso solicitado refiere a Servicios Turísticos-Recreativos y el mismo está afectado a Urbanización Futura.

${ }^{9}$ Resulta interesante que, en relación a este último punto, se menciona también la satisfacción de algunos vecinos por el funcionamiento del emprendimiento - centralmente, en función de los servicios laborales a prestar - y la realización de una encuesta domiciliaria en los inmuebles que están frente al predio en cuestión.
} 
exigiendo la restitución inmediata del inmueble (Argentina, 1998).

En los años siguientes surgen una serie de denuncias alrededor de diversas actividades desarrolladas en la Canchita de los Bomberos: desde la instalación de un circo durante la temporada estival, pasando por el funcionamiento de un camping clandestino, hasta la ocupación de forma esporádica o bien permanente.

Posteriormente, en el año 2009, el Organismo Nacional de Administración de Bienes del Estado trasfiere parte del predio al gobierno de la Provincia de Buenos Aires para la construcción del Museo de Arte Contemporáneo. En tal sentido, la iniciativa coincide con otras acciones del municipio en política urbana, orientadas a la valorización de zonas consideradas estratégicas, a través de crecientes procesos de privatización del espacio público (Playas Bristol y del Sur), la recalificación de centros comerciales (Constitución, Alem, Güemes) y la construcción de equipamientos de jerarquía (Estación Ferroautomotora y el mencionado Museo).

Un año después, en 2010, se aprueba el marco urbanístico del "Plan Particularizado de Desarrollo" del sector, que implica tanto la construcción del Museo como la del Distrito Descentralizado Norte y la posibilidad de catastrar parte de la zona para vivienda multifamiliar y/u hotel de categoría no inferior a tres estrellas (Argentina, 2010). Días antes de la resolución, algunos vecinos manifiestan su malestar reclamando por la existencia de espacio verde en el lugar. "Esa ordenanza contempla el museo, una sede para la descentralización de la Municipalidad, la cual es muy importante, pero también indica que podría haber un hotel cinco estrellas y edificios, nada tiene que ver con nuestra intención y con lo que nos habían dicho. Nos oponemos rotundamente a todo esto", declara Cristina Rojo, presidenta de la Sociedad de Fomento del Barrio Parque Luro, a un medio local. Haciendo hincapié en las dificultades que acarrearía en la infraestructura barrial, agrega que "la lucha por la plaza sigue" (El Diario de Mar del Plata y la región, 2010).

Finalmente, se construye el Museo que recientemente se inauguró. También continúan desarrollándose iniciativas privadas en la zona, en general, edificando sobre la costanera. Paralelamente, se desestima lo que se concretó para el Distrito Norte, buscándose una localización alternativa. Pero, sin dudas, las principales disputas se vinculan al proyecto urbanístico de construcción de viviendas en el lugar, enmarcadas en el PRO.CRE.AR.

\section{Acerca del proceso de territorialización del conflicto}

Algunas características sobre la implementación del PRO.CRE.AR en Mar del Plata

El fondo público fiduciario PRO.CRE.AR se crea en junio de 2012 con el objetivo de "facilitar el acceso a la vivienda propia de la población y la generación de empleo como políticas de desarrollo económico y social" (Argentina, 2012, p. 3) ${ }^{10}$. En septiembre se anuncian las tierras disponibles que pueden quedar comprometidas bajo la modalidad desarrollo urbanístico ${ }^{11}$; entre ellas está el predio conocido como "Canchita de los Bomberos", en la ciudad de Mar del Plata, donde se prevé construir apartamentos monoambientes y dúplex, en terrenos aportados por el Estado nacional.

Pocos días después del anuncio, se conforma un grupo de vecinos autoconvocados en defensa de la utilización del predio como espacio público, y contra la construcción de viviendas, atendiendo además al impacto demográfico que podría ocasionar en el crecimiento poblacional de la zona. En este contexto, se reúnen vecinos con autoridades de Municipio de General Pueyrredón12, Administración Nacional de Seguridad Social,13 Ministerio de Economía y Banco Hipotecario, con el fin de conocer el proyecto e intentar alcanzar algún consenso sobre el mismo. Desde el MGP se reitera la intención de conservar los espacios

10 "PRO.CRE.AR BICENTENARIO es una iniciativa del Gobierno Nacional que proyecta la entrega de 400 mil créditos hipotecarios para la construcción, ampliación, terminación y refacción de viviendas, como así también para adquirir aquellas que son construidas por el Programa a través de desarrollos urbanísticos". Posteriormente, se añade la compra de terreno y la adquisición de viviendas a estrenar.

${ }^{11}$ A la fecha, esta modalidad aún no está habilitada para la inscripción de los posibles beneficiarios ya que, estando judicializado este conflicto, no hay destino alternativo definido.

12 En adelante, MGP.

${ }^{13}$ En adelante, ANSES. Es uno de los principales organismos que participa del financiamiento del Programa, junto al Ministerio de Economía y Finanzas Públicas y a otros inversores privados. 
verdes, previéndose que del total de la superficie quede un $70 \%$ de plaza pública y un $30 \%$ de viviendas (Argentina, 1933) ${ }^{14}$.

Mientras tanto los Colegios de Arquitectos, como el de Martilleros, muestran ciertos reparos con la propuesta, recogiendo parcialmente los argumentos de los vecinos autoconvocados, quienes además recurren a los servicios de un abogado para una posible demanda judicial, pues cuestionan la legalidad del proceso. El letrado José Esaín, especialista en derecho ambiental, considera que la selección de ese predio "está viciada" ya que "no se cumplió con lo establecido por la ley provincial que exige la realización de una evaluación de impacto ambiental [...] El error es que no han evaluado los impactos y tampoco tuvieron en cuenta el valor ambiental urbanístico que tiene el predio" (El Diario de Mar del Plata y la región, 2012b).

Pasados cuatro meses, y vencido el plazo para la licitación de las obras, las protestas no cesan. Ahora es el propio Ejecutivo municipal quien descarta la idea original de construir allí el Distrito Descentralizado Norte y ofrece como alternativa la creación de un parque público junto al proyecto de desarrollo urbanístico, con el intento de apaciguar la oposición vecinal.

Sin embargo, lejos de lograr un consenso - e incluso a pesar de las modificaciones que se producen al proyecto original - la postura de los vecinos se mantiene firme y recurren a la justicia presentando un recurso de amparo, a través de la Sociedad de Fomento Parque Luro, en el Juzgado Correccional № 4 y, asesorados por el letrado intiman al municipio para que realice una evaluación del impacto ambiental en el predio y que, mientras tanto, se detengan las obras.

Los siguientes días continúan con denuncias sobre los supuestos incumplimientos del municipio y, ante la llegada de operarios de la empresa constructora (COARCO) para alambrar la zona, los vecinos se instalan en la plaza y le exigen a la constructora una autorización judicial. A un mes del inicio del proceso judicial, el 25 de abril de 2013, la Dra. Camadro, titular del Juzgado Correccional № 4, dicta una medida cautelar a favor de los vecinos, ordenando al MGP la

\footnotetext{
${ }^{14}$ Asimismo, funcionarios de ANSES explican que se está desarrollando el estudio en cumplimiento de Ley de Medio Ambiente de la Provincia de Buenos Aires (Ley № 11.723) que exige la presentación de Evaluación de Impacto Ambiental, que será cumplimentado con otros que realizarán las empresas a la hora de presentar la propuesta.
}

suspensión de las obras hasta completar el informe de impacto ambiental.

Días más tarde se anuncia la presentación de dicho informe, que daba continuidad al estudio preliminar elaborado en octubre de 2012, el cual aparece en el pliego de condiciones del concurso para la construcción de viviendas promovido por el Banco Hipotecario. Todo ello con la intención de que se levante la medida cautelar, y se pueda así avanzar con las obras. Sin embargo, casi un mes después de que dicha medida haya sido dictada, la Cámara Contencioso Administrativa reafirma la misma y rechaza la apelación presentada por el MGP. En resumen, la sentencia presenta tres disposiciones: "1. Hacer lugar a la acción de amparo, 2. Invalidar el proceso de Evaluación de Impacto Ambiental15, 3. Imponer costas a la Municipalidad de General Pueyrredón" (Vecinos Autoconvocados Canchita de los Bomberos, 2013, p. 5).

A raíz de ello, el Secretario de Obras y Planificación del MGP expresa que el municipio va a responder a la causa, contando tanto con la declaración de impacto ambiental extendida por la Dirección de Gestión Ambiental como con los planos aprobados. Por tanto, si bien no hay posibilidad de comenzar las obras hasta que la justicia no resuelva en sentencia firme, se sigue considerando construir en la Canchita de los Bomberos; no obstante, han comenzado a evaluar terrenos alternativos para avanzar con las obras del PRO.CRE.AR.

Sin embargo, a pesar de que el MGP apeló la sentencia en primera instancia, la Cámara de Apelación de lo Contencioso Administrativo acaba, el 24 de octubre de 2013, tras considerar la petición de los vecinos, resolviendo a su favor en sentencia firme.

\section{Sobre representaciones e imaginarios en tensión}

El proceso descrito remite a un cúmulo de acciones que guían las prácticas de los principales actores involucrados en la disputa. Es decir, son emergentes de una diversidad de representaciones e imaginarios urbanos, de puntos de vista (Bourdieu, 2002), que subyacen en el conflicto sobre la construcción de

\footnotetext{
${ }^{15}$ No sólo es necesario el estudio de impacto ambiental y de prefactibilidad para definir el emplazamiento, sino además someterlo a una audiencia pública.
} 
viviendas en el predio de la Canchita de los Bomberos: sea a favor, en contra o, incluso, en tensión.

Baeza sostiene que "los imaginarios sociales son múltiples y variadas construcciones mentales (ideaciones) socialmente compartidas de significancia práctica del mundo, en sentido amplio, destinadas al otorgamiento de sentido existencial" (Baeza, 2003 apud Hiernaux, 2008b, p. 18). En particular, los imaginarios urbanos, en palabras de Hiernaux (2008b, p.18), "son fruto de la capacidad humana para representarse la ciudad a partir de imágenes que se presentan de ella al individuo y la sociedad y transformar esa representación en un imaginario actante, es decir, actos guiados por la imaginación".

A partir de la sistematización de la información relevada, podemos definir ciertas categorías de análisis en las que se plasman imaginarios actantes; en definitiva, se hallan en disputa diversas representaciones del espacio, las cuales inciden en las prácticas de los individuos. Tales formas de apropiación simbólica se refuerzan o modifican en función del conflicto, delimitando así el proceso de territorialización (Mele, 2003). Ellas son: la concepción del espacio público, la apelación al pasado o el mito de origen, la alusión a lo político, y las tensiones en torno a la valorización del espacio.

\section{La concepción del espacio público}

La alusión al espacio público se convierte en el eje nodal del conflicto. Desde los vecinos autoconvocados se asumen una diversidad de acepciones. En general, como sinónimo de "nuestro espacio verde", "de uso comunitario", como un bien colectivo que merece ser defendido apoyándose en argumentos legales. Incluso sostienen que históricamente han sido los únicos que lo han mantenido como tal: "con los primeros reclamos de la plaza llegamos hasta el día de hoy con los vecinos defendiendo el predio y, en ese sentido, no debemos perder de vista que tampoco los vecinos pueden cumplir el rol que tiene que cumplir el Estado". Así, justifican su actuación frente a los déficits del municipio, entendiendo que la propuesta de mantener la plaza "tendría que haberse originado desde el Estado ${ }^{16}$. Este argumento del espacio público

\footnotetext{
16 Palabras de Arq. Ondartz, coautor del informe "Impacto...". Charla de presentación, 29/04/13. Ver la nota 7.
}

es cuestionado por otros vecinos del barrio, quienes se manifiestan a favor de la construcción de viviendas, ya que consideran que el Estado, como propietario de las tierras, es quien puede decidir el destino y uso que considere más conveniente.

La presuposición de que es un asunto de la comunidad de vecinos se pone en tensión en el momento en que trasciende el espacio barrial y se lo define como un espacio de la ciudad. Así, refieren que "no solamente hay que tomar la cuestión de la Canchita de los Bomberos como una cuestión de índole barrial sino que hay que tomarlo como una cuestión ciudadana, o sea, una cuestión de los marplatenses"17. Tanto desde la perspectiva técnica, por estar situada dentro de la franja costera, como desde la perspectiva simbólica, para ser usado y disfrutado por todos los marplatenses e, incluso, por los turistas. "Desde Plaza España hasta Camet no hay un solo espacio público y ahora lo estaríamos perdiendo [...] se está cambiando un extremo de la cuerda por otro extremo: este espacio verde y de todos se convertiría en uno completamente cementado y privatizado" (El Diario de Mar del Plata y la región, 2013c) ${ }^{18}$, dice Esaín, abogado patrocinante de los autoconvocados.

En relación a las críticas que reciben ciertos argumentos, que parecen estigmatizar a los posibles beneficiarios de las viviendas, los vecinos autoconvocados aclaran que ellos no se oponen al programa en sí mismo sino a su emplazamiento: "es en un sentido positivo que hay que hablar no en detrimento del Pro. Cre.Ar sino a favor del espacio verde para todos los marplatenses y para la ciudad de Mar del Plata"19. En esa línea, sugieren que el destino debiera garantizar igualdad, a pesar de que sus prácticas lo ponen en duda: "No es una cosa u otra. Es la playa, la plaza, las viviendas y el trabajo, pero cada cosa en su lugar [...] queremos dejar en claro una vez más que el espacio público que se defiende es aquel que tiende fundamentalmente a la mezcla social, el que de su uso permite un derecho ciudadano de primer orden, así el espacio público debe garantizar en términos de igualdad la apropiación por parte de diferentes colectivos sociales y culturales, de género y de edad" (Diario El Atlántico, 2012).

${ }^{17}$ Palabras de Arq. Fernández Bravo, coautora del informe “Impacto...." Charla de presentación, 29/04/13. Ver la nota 7.

18 A. B. Comentario hecho en el Portal de Noticias 0223.com. ar, 26/10/13.

${ }^{19}$ Palabras de Arq. Fernández Bravo, coautora del informe “Impacto...." Charla de presentación, 29/04/13. Ver la nota 7. 
Destacan la importancia del acceso a la vivienda pero también cierta calidad de vida; por ello, mencionan la existencia de lugares alternativos para llevar adelante el programa habitacional. E incluso llegan a proponer que "entre los baldíos y las casas en venta del barrio se podría satisfacer la demanda de 220 viviendas (y aún más) y al mismo tiempo conservar la plaza y la fisonomía del barrio" (Change, 2013). En esa misma línea, uno de sus asesores profesionales sostiene que la vivienda colectiva ya ha fracasado, hallándose muchas áreas sobre densificadas y atravesando procesos de desvalorización.

\section{La apelación al pasado o el mito de origen}

Los vecinos autoconvocados aluden constantemente a que la donación del inmueble que había realizado la familia Unzué tenía un fin específico: el benéfico. Ese argumento, ligado al "origen" del predio, es el que otorga legitimidad al reclamo. De él se desprenden otros fines, que remiten de diversas formas a la finalidad benéfica, con los que se pone en jaque el papel desempeñado por el Estado en su cumplimiento. Los autoconvocados consideran que el Estado se ha apropiado de las tierras, y es necesario "hacerle entrar en razón".

Entre otros motivos, destacan que la disputa por la plaza se remite a la década de 1950, cuando se presentó un proyecto de parquización de la zona, y que posteriormente fue archivado. Incluso al relatar algunos de los usos del predio, que anteriormente señaláramos, expresan que "sobre este terreno los vecinos siempre se manifestaron. No es que esto es algo nuevo. Los vecinos vienen viviendo y reclamando la plaza desde el $50^{\prime 20}$.

Uno y otro argumento - la finalidad originaria y el reclamo por el espacio público - aparecen unificados de manera recurrente: "Que se respete el espacio verde que desde hace más de 80 años disfrutan todos los vecinos" (Diario El Atlántico, 2012).

Sin embargo, el propio intendente pone en duda la canalización de esta demanda a través de la vía institucional: "Si bien nunca existió un proyecto de una plaza para ese lugar -porque nunca hubo una iniciativa de algún legislador o de algún particular en tal sentido, aclaró- sí advertimos que se despertó una inquietud reciente entre los vecinos que queremos recoger y

\footnotetext{
${ }^{20}$ Entrevista a vecinos autoconvocados, 13/04/13.
}

considerar"(La Capital MDP, 2013b). En relación a la concreción del proyecto de plaza frente al Museo de Arte Contemporáneo, un portal de noticias locales dice que un alto cargo municipal se expresó así: "Ahora van a tener un espacio verde. Ya no pueden decir nada, salvo que reconozcan que no quieren esas casas ahí" (El Diario de Mar del Plata y la región, 2013a).

En esa misma línea argumentativa, otros vecinos del barrio, - que se manifiestan a favor de la ejecución del PRO.CRE.AR en la zona, refutan el argumento de los autoconvocados y dicen que el predio siempre estuvo abandonado. "En la Canchita jugaron mis hijos, cuando era aprovechada por varios clubes deportivos y colegios de la zona, quienes se encargaban de su mantenimiento. Luego, aquellas instituciones adquirieron sus propios campos deportivos en otros lugares de la ciudad y la Canchita fue poco a poco convirtiéndose en tapera, depósito de basuras, nidal de roedores y asiento de casillas precarias. Y así se mantuvo por largos años"21. Incluso sostienen que, si bien fracasó la propuesta de realizar un centro de convenciones, no fue por la oposición de la Sociedad de Fomento Parque Luro. "Es recién ahora, cuando se corre el riesgo de darle un destino que beneficie a familias integradas por ciudadanos con iguales derechos a los de la "gente como uno" pero aún carentes de la oportunidad de acceder al derecho fundamental a poseer una vivienda digna, cuando el vecindario se alarma, se indigna, protesta legalmente y se ocupa de mantener la Canchita hecha un primor"22.

Y aún más: destacan que aquellos que hoy se oponen, anteriormente "nunca se quejaron" de otros hechos sucedidos en el predio; y que incluso con la instalación de Museo de Arte Contemporáneo "no dijeron nada"23.

\section{La alusión a lo político}

La utilización del conflicto como recurso político predomina en el discurso de los vecinos autoconvocados. Para ellos es en ese ámbito donde se generó la disputa: "parece que el conflicto lo hubiésemos generado nosotros, ¿viste? Y, en realidad, se genera a partir de

\footnotetext{
${ }^{21}$ M.S, vecino del barrio desde hace 40 años. Comentario hecho en el Portal de Noticias 0223.com.ar, 25/10/13.

22 Idem.

${ }^{23}$ H.M., vecino del barrio desde hace 30 años. Comentario hecho en el Portal de Noticias 0223.com.ar, 25/10/13.
} 
que los que, realmente, gestionan políticas de Estado lo hacen como si fuese la ciudad suya. Y nunca es escuchando a los ciudadanos, que son los que están sufriendo, de alguna manera, esa cuestión porque si vos pagás los impuestos están sosteniendo ese tipo de gestión"24.

Así, en principio, lo político aparece cuestionado responsabilizándose a los sujetos ("los políticos") que lo gestionan. En tal sentido, el letrado que asesora a los vecinos que se resisten a la construcción de las viviendas expresa "Aquí hay un error en la toma de decisión del proyecto de construcción de viviendas en un espacio verde, que para los funcionarios municipales es un baldío que cumple con todas las normas para ser edificado, pero para los vecinos significa la única plaza en la zona"(El Diario de Mar del Plata y la región, 2012b).

Asimismo, los autoconvocados manifiestan no haber tenido ningún tipo de acercamiento "excepto por ahí del bloque de Arroyo (concejal), que opinan como nosotros ${ }^{\prime 25}$. Otro concejal (Rodríguez), vecino del barrio, presenta un proyecto de ordenanza solicitando al Ejecutivo que intermedie ante el gobierno nacional para relocalizar el proyecto de construcción de viviendas (Lo que pasa.net, 2013).

Sumado a ello, destacan la desinformación tanto de los funcionarios municipales como de otras dependencias estatales involucradas en el programa. Cuestionan incluso su desempeño, tanto en lo que respecta a la definición del proyecto como al supuesto acuerdo negociado subyacente a él. Por estos motivos, una vez que la justicia falla en segunda instancia, se plantean un posible enjuiciamiento de los funcionarios involucrados en la decisión. "Fueron muchos años de este conflicto. Ahora que la Justicia nos dio la razón, creo que deberíamos accionar contra los funcionarios municipales que hicieron todo mal. Que vayan presos sabemos que es imposible, pero al menos que respondan con su patrimonio - dijo un vecino, con el casco rojo de bomberos, en la asamblea que los vecinos de Parque Luro tuvieron este viernes por la mañana”(El Diario de Mar del Plata y la región, 2013b).

Finalmente, se entiende la política en un sentido abstracto, casi despolitizado. "Quisimos de alguna manera cuidarnos de posicionarnos políticamente"26.

\footnotetext{
${ }^{24}$ Entrevista a vecinos autoconvocados, 13/04/13.

${ }^{25}$ Entrevista a vecinos autoconvocados, 13/04/13.

${ }^{26}$ Entrevista a vecinos autoconvocados, 13/04/13.
}

La política se ve incluso separada del plano jurídico que, perjudicada por las "malas decisiones" de los políticos que infringieron la ley, avasallando derechos; la política aparece con una entidad suprema: "la justicia dijo no" a los gobiernos provincial y municipal.

En la posición opuesta están quienes, manifestándose a favor del proyecto, sostienen que fue precisamente la justicia la que se excedió en sus funciones: "falla casi siempre a favor de los cipayos en estos casos, ya nos acostumbramos a eso"(El Diario de Mar del Plata y la región, 2013b). ${ }^{27}$

\section{Las tensiones entorno a la valorización}

La cuestión de la valorización del espacio genera diversas controversias. Los vecinos autoconvocados sostienen, mayoritariamente, que la implementación del PRO.CRE.AR acarrearía una desvalorización, mientras que por otro lado hablan del intento de revalorización que habría detrás del propósito de concretar el desarrollo urbanístico. En tal sentido, la ejecución del plan oscilaría entre un proceso de revalorización-desvalorización.

Se alude a la desvalorización del barrio tanto desde dos dimensiones: la material y la simbólica. Desde una dimensión material, se argumenta el impacto que tendría en la infraestructura del barrio "Son 221 viviendas y 245 cocheras, cocheras subterráneas [...] son entre 1.200 y 1.500 personas. Eso es lo que hablamos, ¿no? de golpe. En promedio, la incidencia dentro del barrio, en promedio, es un crecimiento del 14\%". Cuando bajo parámetros "normales" el crecimiento demográfico es del $3,5 \%$ anual. ${ }^{28}$ Los vecinos autoconvocados consideran que la infraestructura actual es deficiente ${ }^{29}$.

\footnotetext{
${ }^{27}$ AR. Comentario hecho en el Portal de noticias 0223.com. ar, 25/10/13.

${ }^{28}$ De acuerdo con la Dirección de Estadística (MGP), en 1991 Parque Luro tenía 9.041 habitantes, en 2001 la cifra ascendía a 10.189 y para 2010 alcanzaba las 11.353 personas. Ello significa que el crecimiento poblacional - en términos relativos, una variación intercensal de 12,69\% y 11,42\% respectivamente - se viene produciendo desde hace algunas décadas y ha demostrado una merma en el último período.

29 “Se midió al revés: necesitamos las viviendas, las ponemos en un lugar que es deficitario [...] Es deficitario en cuanto a red de agua potable. Con la luz tenemos problemas porque no sabemos cuál es la antena que distribuye acá pero cada
} 
Asimismo, se hace énfasis en el proceso de desvalorización que atraviesa el sector en términos comparativos, si lo comparamos con la zona sur que ha atraído otro tipo de inversiones "Desde hace años, la zona norte viene sufriendo una serie de consecuencias producto de obras que se han realizado al sur de la ciudad [...]30 la zona sur [...] tiene un montón de inversiones puestas en espacios públicos que en la zona norte nunca, nunca se hicieron. 0 sea, la zona norte siempre fue producto de la decisión de lo que había que solucionar para toda la ciudad pero nunca específicamente hubo una propuesta para la zona norte ${ }^{31}$.

En tal sentido, atendiendo a los argumentos esgrimidos por los vecinos que se oponen al proyecto, los promotores del proyecto destacan que "La línea arquitectónica es coherente con la del Museo de Arte Contemporáneo, lo que revaloriza la zona y le da más valor, aún a las construcciones preexistentes [...] La idea es que los que allí vivan puedan, a su vez, disfrutar de un área de esparcimiento realmente amplia [...] le agrega valor a toda la zona, además de solucionar los problemas de vivienda de muchas personas, generando un círculo virtuoso en el que se conjuga el diseño, la comodidad y el área verde al alcance de todos los vecinos" (La Capital MDP, 2013a) ${ }^{32}$.

Desde una dimensión simbólica, recogiendo la preocupación por el déficit infraestructural, los vecinos autoconvocados ponen el foco en los perjuicios que implicaría para los beneficiarios del PRO.CRE.AR vivir allí. "[...] a lo que lo van a traer es, realmente, a un lugar muy deficitario y que le van a hacer pagar el departamento muchísimo más de lo que podrían pagarlo en cualquier otro sector de la ciudad en forma

tanto, en verano, por ejemplo, con un aumento por turistas, que sería mucho menos que esto, nos quedamos sin luz cada dos por tres. La presión de gas en invierno es poca. Con lo cual, cuando vos no tenés la cantidad de metros cúbicos, tenés baja presión no te llega el gas como debe llegar". Entrevista a vecinos autoconvocados, 13/04/13.

${ }^{30}$ Entre otros, se mencionan las consecuencias de la construcción de espigones en el Puerto (Sur) que provocó una pérdida de arena muy grande para las playas del Norte; la localización de la planta de efluentes cloacales que trajo altos niveles de contaminación para las mismas, etc.

31 Palabras de Arq. Fernández Bravo, coautora del informe "Impacto...." Charla de presentación, 29/04/13. Ver la nota 7.

32 Entrevista a Diego Bossio, titular de ANSES. Diario La Capital, 13/03/13 y $17 / 03 / 13$. independiente" ${ }^{\prime 33}$. Ello se vincula además a la tensión que se generaría entre la "población receptora" y "la población que se agrega" en relación a la disputa por los escasos recursos existentes en el barrio: “[...] aparte de los servicios, ¿qué va a pasar con todo lo demás? Tan simple como vas a ir a comprar pan y ya no hay porque... "no, tenés que venir antes de las 11 ". Es decir, modifica el día a día, el minuto a minuto es modificado por la cantidad de población [...] La inclusión tiene que ver con esto: la sociedad receptora recibe al nuevo, el nuevo adapta su comportamiento y entre los dos forman una nueva línea de comportamiento. Pero estamos hablando de casos que se van incluyendo. Y esto es directamente una inserción, es un golpe, es: que se adapte la población nueva y la receptora a como dé lugar, ¿viste? Y las cosas no son tan simples ni tan rápidas, sobre todo cuando va a haber conflicto por los recursos. Esto no lo midió nadie"34.

Por su parte, el Colegio de Arquitectos se manifiesta a favor del PRO.CRE.AR pero reconoce la complejidad de la provisión de tierra sosteniendo que "el Estado, fundamentalmente el Municipal, debe planificar adecuadamente la decisión de asignación de tierra pública a la realización de estos emprendimientos, no puede ni debe caer en la determinación reduccionista de otorgar los lotes 'disponibles' sin considerar si son los 'adecuados'”. Así, sugiere la revisión del proyecto y la evaluación de otras alternativas que no acarren conflictos sociales $(0223,2012 a)$. También desde el Colegio de Arquitectos de Martilleros se ponen reparos al proyecto, sosteniendo que "Mar del Plata necesita espacios verdes" y que, además de "consultar y escuchar a todos los vecinos", debe mantenerse una coherencia con el lindero Museo de Arte Contemporáneo "que va a ser orgullo de la ciudad y atraerá al turismo cultural”.35

En la posición opuesta están aquellos vecinos del barrio que se manifiestan a favor del proyecto y que consideran que éste es un argumento discriminatorio. "Sumá los espacios verdes (jardines en el frentey fondo) de todas las casas de nuestro barrio, más las redes pluvial, cloacal, de gas, de agua corriente ya instaladas, más la escasa altura de las edificaciones del proyecto

\footnotetext{
${ }^{33}$ Entrevista a vecinos autoconvocados, 13/04/13.

${ }^{34}$ Entrevista a vecinos autoconvocados, 13/04/13.

35 Palabras del presidente del Colegio profesional, Miguel Donsini. Portal de Noticias 0223.com.ar, 15/10/2012. Ver la nota 7.
} 
( ¿es un lujo proveerlas de los servicios esenciales y de ambientes confortables, o ellos están reservados a las clases medias altas y altas?), y luego evaluá cuál es la magnitud del impacto ambiental [...] a mí me parece que hay un importante componente de discriminación social en muchas de las protestas y reclamos contrarios a la ubicación de este proyecto de PRO.CRE.AR" (El Diario de Mar del Plata y la región, 2013b) ${ }^{36}$.

\section{Efectos de ciudad}

Nos hemos propuesto analizar el proceso de territorialización (Mele, 2003) que se genera a partir de un conflicto derivado del posible destino de un predio para la construcción de viviendas en el marco del PRO.CRE.AR. Para ello, hemos intentado captar los diversos puntos de vista para confrontarlos (Bourdieu, 2002); en definitiva, para comprender las diferentes formas de apropiación simbólica que se refuerzan o modifican en función de la disputa.

Con esa finalidad, abordamos los imaginarios urbanos como productores de actos guiados por la imaginación, distanciándonos de aquellos enfoques donde prevalece la representación de la ciudad sin interrogarse sobre las implicancias que ello tiene sobre las prácticas de los individuos en el espacio urbano (Hiernaux, 2008b).

En función de la sistematización del trabajo de campo, delimitamos cuatros categorías para pensar en los imaginarios que se cristalizan en la disputa: la concepción del espacio público, la apelación al pasado o el mito de origen, la alusión a lo político, y las tensiones entorno a la valorización del espacio. A grandes rasgos, podemos afirmar que a partir de ellos se produce un "choque de imaginarios" (Hiernaux, 2008a, p. 11) ${ }^{37}$

\footnotetext{
${ }^{36}$ M.S, vecino del barrio desde hace 40 años. Comentario hecho en el Portal de Noticias 0223.com.ar, 25/10/13.

${ }^{37}$ Hiernaux (2008a) se refiere a la relación entre los imaginarios de urbanistas y planificadores urbanos, que se plasma en proyectos urbanísticos, y los imaginarios acerca de la vida urbana de los habitantes de esos espacios. Como consecuencia, se produce el choque de imaginarios, cuyo resultado se visualiza en las prácticas cotidianas de los habitantes de dicho espacio. Si bien abordamos un proceso distinto, creemos que tiene una capacidad explicativa para dar cuenta de cómo se (re)construyen los diversos imaginarios en relación al espacio disputado, logrando imponerse unos sobre otros.
}

como resultado de las diversas representaciones que los actores producen y (re)producen en la disputa por la apropiación simbólica del espacio en cuestión y que se hallan en tensión.

Por una parte, se distingue la producción de un imaginario dominante o colonizador (Hiernaux, 2008a, 2008b). Éste emerge, principalmente, de las representaciones de los vecinos autoconvocados $\mathrm{y}$ alternativamente de otros actores que apoyan su demanda (Colegios de Arquitectos, Colegio de Martilleros, etc.). Si bien ellos se perciben a partir de estrategias de resistencia - básicamente, a la ejecución de una política pública -, lo hacen a partir de prácticas tendentes a reforzar una dinámica crecientemente segregativa. En tal sentido, como sostiene Oslender "no todas las resistencias se dejan clasificar como "progresivas". De hecho, algunas resistencias refuerzan estructuras existentes de dominación y sujeción" (Oslender, 2002, p. 9).

Este imaginario dominante se construye alrededor de la tríada "espacio público-verde-comunitario" y se encuentra amenazado. No sólo en relación al (supuesto) déficit infraestructural de su entorno sino, centralmente, en función de la imposibilidad de conservar lo que han elegido: "una vida apacible, en un ambiente limpio y con una vecindad respetuosa de los otros" (Vecinos Autoconvocados Canchita de los Bomberos, 2013). Parafraseando a Bauman (2003), una comunidad imaginada.

Ligada a esa representación aparece una idea de identidad unívoca, que perciben preexistente al conflicto y que pretende conservarse. "Entendemos que este lugar aún tiene una identidad propia dentro de la ciudad de Mar del Plata, con bases culturales, étnicas y geográficas"( Vecinos Autoconvocados Canchita de los Bomberos, 2013, p. 1). La misma se visualiza no sólo en relación a los beneficios que ello acarrea para el barrio en particular, sino que trasciende y permea la definición de la ciudad misma, con pretensiones de legitimarse en la "ciudadanía marplatense", e incluso, en el turista. Además, se descalifican los argumentos de quienes se manifiestan en favor del proyecto: "Muchos por desconocimiento y sin ningún tipo de argumentación válida, intentan quitar legitimidad al reclamo de la conservación del espacio público como plaza [...]”(Vecinos Autoconvocados Canchita de los Bomberos, 2013, p. 1)

Son estos elementos los que conforman centralmente un imaginario dominante, que se transforma en actante

urbe. Revista Brasileira de Gestão Urbana (Brazilian Journal of Urban Management), 2015 maio/ago., 7(2), 237-249 
y orienta las prácticas de los vecinos autoconvocados. Esto se vincula a que, en palabras de Melé (2003 apud Azuela \& Cosacov, 2013, p. 156), los conflictos territoriales suponen "un trabajo colectivo en torno a las representaciones de los usos legítimos del espacio y una definición territorial que delimite el espacio que es preciso proteger y preservar de ciertas dinámicas". Sin duda, un elemento central aquí es el de las estrategias de visibilización que los autoconvocados ponen en juego: amplia difusión de la problemática, realización de actividades en el predio, búsqueda de adhesiones entre otros actores, asesoramiento profesional, marchas a tribunales y al municipio, entre otros. El punto culminante de esta práctica es la judicialización del conflicto, a partir de la presentación de un recurso de amparo, que cuenta con una sentencia firme en segunda instancia.

Todo ello coadyuva a la irrupción del conflicto en el espacio público, que constituye otra de los ángulos del análisis de la productividad social que propone Mele (2003). En tal sentido, si bien con pretensiones analíticas, resulta casi imposible escindir el proceso de territorialización de dicha irrupción, mientras el concepto de imaginario actante amalgame tal vinculación. A pesar de pretender despolitizar la política, sólo ha sido gracias a la construcción de un espacio político que los vecinos autoconvocados lograron interpelar las decisiones políticas-estatales, y terminaron reforzándolo con el discurso jurídico a su favor. En definitiva, como sostiene Mele, la productividad de los conflictos urbanos es territorial, jurídica y política.

También identificamos un imaginario de resistencia que sostiene una representación distinta del territorio en cuestión, que encuentra su legitimidad en dos defensas: la del derecho a la vivienda, que se viabilizaría para las familias beneficiarias del programa; y, en menor medida, la de la ciudad, centrado en la crítica a la estigmatización subyacente al discurso de los autoconvocados que manifiestan su perjuicio por la ejecución del PRO.CRE.AR en ese predio, pero no lo hicieron en el momento de destinarse parte de él a la construcción del Museo de Arte Contemporáneo. Estas representaciones, si bien son compartidas alternativamente por una diversidad de actores (vecinos del barrio, posibles beneficiarios, funcionarios de gobierno), no logran plasmarse en un argumento sólido que dispute la definición de otro imaginario dominante, subvirtiendo la situación actual ${ }^{38}$.

Considerando que el caso abordado se constituye, parafraseando a Bachelard (apud Bourdieu, 1997), como "particular de lo posible", y que ilustra así las tensiones que moldean la ciudad, la construcción de un imaginario dominante refuerza una dinámica urbana segregacionista que se disimula bajo diversos argumentos, fundamentalmente ambientales aunque también económicos y sociales. En definitiva, en términos de su productividad social, la mirada que prevalece en el conflicto naturaliza el binomio "distancia social-distancia espacial", como si la categoría de beneficiario de una política de vivienda se asociara, parafraseando al ya clásico trabajo de Oszlak (1991), al merecimiento de sólo algunos lugares de la ciudad, jerarquizando el espacio urbano y restringiendo el derecho a ella sólo para quienes pueden acceder desde una lógica privada.

\section{Referencias}

Argentina (1933, 28 de septiembre). Ley $N^{\circ} 11.723$ de 28 de septiembre de 1933 sobre el Régimen Legal de la Propiedad Intelectual (Ley sobre el Derecho de Autor, modificada por última vez por la Ley № 26.570 de 25 de noviembre de 2009). Buenos Aires: El Senado y Cámara de Diputados de la Nación Argentina.

Argentina (1985, 11 de septiembre). Ordenanza municipal 6331, sancionada el 29 de agosto de 2012. Desafecta del Distrito de Uso Residencial varias parcelas afectandolas al Distrito de urbanización Futura (UF) para la construcción de un Centro de Convenciones y Congresos Nacionales e Internacionales con Sala de Concierto y Hotel de 5 Estrellas. Abrogada por Ordenanza 11150. Buenos Aires: Partido de General Pueyrredon.

Argentina (1990, 28 de septiembre). Ordenanza municipal 7896, sancionada el 13 de septiembre de 1990. Declara de interés municipal las fracciones de tierra no construídas de propiedad de los gobiernos nacional y provincial y de sus empresas y organismos descentralizados, ubicados en el Pdo. de General Pueyrredon; de los cuales se requerirá la

\footnotetext{
${ }^{38}$ Habiendo contactado con potenciales beneficiarios del desarro llo urbanístico, éstos no quisieron ser entrevistados, y sólo manifestaron la sensación de "fracaso", por intereses mezquinos, en este derrotero que es el acceso a la vivienda propia.
} 
transferencia sin cargo, para incorporarlos al patrimonio municipal; asimismo, se requerirá la inscripción de todas las tierras previstas por la Ley 9533 y concordantes. Buenos Aires: Partido de General Pueyrredon.

Argentina (1991, 23 de mayo). Ordenanza municipal 8212, sancionada el 23 de mayo de 1991. Dispone que el Departamento Eejecutivo gestione en forma urgente ante el Estado nacional la cesión de fracciones fiscales que identifica y toda otra no construída, dentro del municipio. Asimismo, comunicará al Estado nacional y a los eventuales interesados en la adquisición de dichas fracciones, la vigencia de las normas que regulan los usos y factores de ocupación de las mismas. También requerirá de los organismos correspondientes información sobre la existencia de legados, que establezcan cargos sobre dichos inmuebles. Buenos Aires: Partido de General Pueyrredon.

Argentina (1997, 8 de mayo). Ordenanza municipal 11150, sancionada el 24 de abril de 1997. Establece la normativa urbanística referida al "Centro Cultural de Convenciones y Hotel Cinco (5) Estrellas de la ciudad de Mar del Plata, conforme con las prescripciones regulatorias definidas en la presente ordenanza. Abrogada por Ordenanza 19640. Buenos Aires: Partido de General Pueyrredon.

Argentina (1998, 18 de marzo). Ordenanza municipal 11738, sancionada el 12 de marzo de 1998. Convalida el Convenio de Depósito en Custodia que como Anexo I forma parte de la presente, suscrito entre la Municipalidad de General Pueyrredon y la Dirección General de Bienes del Estado de la Secretaría de Obras Públicas del Ministerio de Obras y Servicios Públicos, por medio del cual el Estado Nacional designa a esta Municipalidad como depositaria en custodia del inmueble propiedad de aquel. Buenos Aires: Partido de General Pueyrredon.

Argentina (2010, 5 de marzo). Ordenanza municipal 19640, sancionada el 4 de marzo de 2010. Establece el marco normativo urbanístico para el Plan Particularizado de Desarrollo del sector delimitado por las calles Floribelo Acosta, Lopéz de Gomara, José Mármol y Avda. Félix U. Camet, el cual incluye bienes del Estado Nacional. Buenos Aires: Partido de General Pueyrredon.

Argentina (2012, 13 de junio). Decreto 902/2012, de 12 de junio de 2012. Créase el Fondo Fiduciario Público denominado Programa Crédito Argentino del Bicentenario para la Vivienda Unica Familiar. Buenos Aires: Boletim Oficial de la República da Argentina, seção 1. Recuperado el 13 de junio de 2012, de http://procrear.anses.gob.ar/ documentos/decreto-procrear.pdf
Azuela, A., \& Cosacov, N. (2013). Transformaciones urbanas y reivindicaciones ambientales. En torno a la productividad social del conflicto por la construcción de edificios en la Ciudad de Buenos Aires. EURE. Revista Latinoamericana de Estudios Urbano Regionales, 39(118), 149-172. http:// dx.doi.org/10.4067/S0250-71612013000300007

Azuela, A., \& Mussetta, P. (2009). Algo más que el ambiente. Conflictos sociales en tres áreas naturales protegidas de México. Revista de Ciencias Sociales, 1, 16, 1-25.

Bauman, Z. (2003). Comunidad: en busca de seguridad en un mundo hostil. Madrid: Siglo XXI.

Bourdieu, P. (1997). Razones prácticas. Sobre la teoría de la acción. Barcelona: Anagrama.

Bourdieu, P. (2002). La miseria del mund. Buenos Aires: Fondo de Cultura Económica.

Canestraro, M. L. (2013). Disputas en torno al proceso de territorialización de un conflicto urbano: el caso de la "Canchita de los Bomberos". In VII Jornadas de Investigación en Antropología Social. Buenos Aires: Instituto de Ciencias Antropológicas, Universidad de Buenos Aires.

Change. (2013). Petición "Intendente Pulti: Conservey equipe la CANCHITA DE LOS BOMBEROS Como PLAZA PÚBLICA". Mar del Plata: Charge. Recuperado el 16 de mayo de 2013, de https:// www.change.org/p/intendente-pulti-conserve-y-equipe-lacanchita-de-los-bomberos-como-plaza-p\%C3\%BAblica?alert_ id=yQRBJKxcBS_kbcGzCkmFU\&utm_campaign=24591\&utm_ medium =email\&utm_source=action_alert

Diario El Atlántico. (2012). La Canchita de los Bomberos no se negocia. Mar del Plata: El Atrantico. Recuperado el 15 de octubre de 2012, de http://www.diarioelatlantico. com/diario/2012/10/15/la-canchita-de-los-bomberosno-se-negocia.html

El Diario de Mar del Plata y la región - 0223. (2010). Vecinos se oponen al negocio inmobiliario que se escondería detrás del Museo de Arte Contemporáneo. Mar del Plata: 0223. Recuperado el 22 de octubre de 2012, de http:// www.0223.com.ar/nota/2010-2-17-vecinos-se-oponenal-negocio-inmobiliario-que-se-esconderia-detras-delmuseo-de-arte-contemporaneo

El Diario de Mar del Plata y la región - 0223. (2012a). Procrear: "El Municipio debe planificar adecuadamente la decisión de asignación de tierra". Mar del Plata: 0223. Recuperado el 22 de octubre de 2012, de http://www.0223. com.ar/nota/2012-10-4-procrear-el-municipio-debeplanificar-adecuadamente-la-decision-de-asignacion-de-tierra 
El Diario de Mar del Plata y la región - 0223. (2012b). Vecinos no descartan ir a la Justicia por la "Canchita de los Bomberos". Mar del Plata: 0223. Recuperado el 29 de octubre de 2012, de http://www.0223.com.ar/nota/201210-27-sigue-la-polemica-por-la-canchita-de-los-bomberos-

El Diario de Mar del Plata y la región - 0223. (2013a). Canchita de los Bomberos: el Municipio hará una plaza. Mar del Plata: 0223. Recuperado el 15 de marzo de 2013, de http://www.0223.com.ar/k/2013-3-14-canchita-de-losbomberos-el-municipio-hara-una-plaza

El Diario de Mar del Plata y la región - 0223. (2013b). Canchita de los Bomberos: vecinos analizan demandar a funcionarios. Mar del Plata: 0223. Recuperado el 10 de noviembre de 2013, de http://app.0223.com.ar/k/2013-1025-canchita-de-los-bomberos-vecinos-analizan-demandara-funcionarios

El Diario de Mar del Plata y la región - 0223. (2013c). Comentario en "Procrear: vecinos de Parque Luro presentaron un amparo". Mar del Plata: 0223. Recuperado el 09 de agosto de 2013, de http://www.0223.com.ar/k/2013-3-26procrear-vecinos-de-parque-luro-presentaron-un-amparo

Hiernaux, D. (2008a). Presentación. Los imaginarios urbanos de la dominación y la resistencia: un punto de partida. Iztapalapa, 29(64-65), 7-12.

Hiernaux, D. (2008b). De los imaginarios a las prácticas urbanas: construyendo la ciudad de mañana. Iztapalapa, 29(64-65), 15-35.

La Capital MDP. (2013a). Anuncian que en breve comenzará la edificación de viviendas cerca del Museo de Arte Contemporáneo. Mar del Plata: La Capital. Recuperado el 18 de marzo de 2013, de http://www.lacapitalmdp.com/ noticias/La-Ciudad/2013/03/17/239102.htm
La Capital MDP. (2013b). Promueven crear nuevas plazas en la ex Villa de Paso y junto al Museo de Arte. Mar del Plata: La Capital. Recuperado el 14 de marzo de 2013, de http://www. lacapitalmdp.com/noticias/La-Ciudad/2013/03/13/238871. htm?ref=ar

Lo que pasa.net. (2013). Canchita de los Bomberos: "Es hora de terminar con los caprichos y plantear alternativas". Mar del Plata: Lo que pasa. Recuperada el 20 de agosto de 2013, de http://www.loquepasa.net/web/?p=20197

Mele, P., Laurre, C., \& Rosemberg, M. (2003). Introduction : conflits, territoires et action publique. In Mele, P., Larrue, C., \& Rosemberg, M. (Eds.), Conflits et territories (p. 13-32). Tours: Presses universitaires Francois-Rabelais; Maison des sciences del'homme.

Neiman, G., \& Quaranta, G. (2006). Los estudios de caso en la investigación sociológica. In I. V. Gialdino (Ed.), Estrategias de investigación cualitativa (p. 213-237). Barcelona: Gedisa.

Oslender, U. (2002). Espacio, lugar y movimientos sociales: hacia una `espacialidad de la resistencia'. Scripta Nova Revista Electrónica de Geografía y Ciencias Sociales, 6(115).

Oszlak, O. (1991). Merecer la ciudad - los pobres y el derecho al espacio urbano. Buenos Aires: CEDES; Humanitas.

Vecinos Autoconvocados Canchita de los Bomberos. (2013). amarlaplaza, Revista Mensual de Vecinos "Canchita de los Bomberos", 9(2).

Recibido: Jul. 15, 2014

Aprobado: Oct. 03, 2014 